\title{
FROM THE EDITOR OF THIS SPECIAL EDITION
}

\section{Advancing Knowledge Through Case Research, Writing and Use-in-Learning}

\section{No New Thing}

'A sower went forth sowing,' Jesus is reputed to have said as he introduced a case to his listeners. By considering a common-place agricultural example and activity, learning could be generated about other situations, or indeed the same situation, should the listeners find themselves in the shoes of the sower. The learners were invited to identify with someone and think about his decisions and actions. The sower was not very precise. Some seed fell in rocky places, some on the hard path, some in the shallow soil, some among the weeds and so on. Some fell in good, fertile, well-cultivated soil that was productive. The audience was invited to transfer the learning to their own lives. The point of this case was not the details of agriculture but the mystery of life.

One of the major advances of the twentieth century in management education has been the adoption of case method in business schools. The method's popularity has come and gone over the years but there has been a gradual increase in the use of teaching cases. The collection of blind refereed cases in this special edition derives from a belief that - as a famous Harvard case writer said in the 1920's - 'wisdom cannot be told.' These cases allow us to stand in the shoes of a manager and make decisions in a carefully constructed but intentionally simplified simulation - based on a real situation. This may lead to skills transferable to other situations, and the special learning that takes place when engaging with a case -learning that is quite distinct from the content of the case itself (Elkin 2002 ). As strategies for learning, there are continuing debates about reality and realism, comprehensive or focussed cases, primary and secondary sources, and about the difference between cases and simulations, as well as other issues. But the writing of cases is of almost as great a significance for researchers in its own right; and indeed may bear greater benefits for the organisations studied.

\section{Advancing Knowledge by Surfacing Data}

Organisations are networks of people. Knowledge exists both within people and between people in organisations. Some knowledge is explicit, known to some or all of the organisational members and stakeholders. Some is tacit, or known and relied on in an inexplicable way. Some knowledge is hidden; some is shared. Some knowledge, individuals may not know they have at all.

One of the benefits to an organisation of having a case writer spend time with them is the knowledge that will surface or become explicit as a result. The type and depth of knowledge gained will be different in different organisations.

A case researcher enters the organisation and seeks patterns of knowledge. By data collection and questioning they help make implicit knowledge explicit, the unconscious conscious. As a result the individuals within the organisation come to understand themselves better and the researcher begins to understand as well. They export the understanding about the particular firm and situation and compare it to more general theory grounded in and based on many research exercises. If there is no general theory, the first strand of a new theory is perhaps formulated. The ideas that are generated by melding research observation and theory are reflected to the organisation. The organisation is changed as a result of the initial intervention. The act of thinking with an independent researcher causes new knowledge to be developed and tacit knowledge articulated. The new melded theory is reflected to the organisation, perhaps changed and re exported. This cycle advances knowledge in a specific way but may also add to general

${ }^{1}$ Elkin, GR 2002, Student learning through case research and writing, Journal of the Australian and New Zealand Academy of Management, $\quad v$ vol. 8 , no. 1 . 
understanding. If a similar investigation is carried out in a number of organisations, gradually a reliable body of knowledge and theory can develop. Over time we are able to refine the theory and may claim to have advanced knowledge.

\section{This Special Case Issue}

The reviewers used the criteria below to evaluate the cases and the teaching notes:

\section{The Case Itself}

- Is the written expression of the case clear, concise and accessible to students with an interest in management?

- Is it an engaging and interesting case, one which is credible and real?

- Does the case relate to theoretical questions that could be explored using the case?

- Is the case of a reasonable complexity for the type of case it is? Is it overwhelmed by irrelevance?

- Do the questions posed help with learning?

- Do the questions lead the student to develop an understanding of events in the case from the perspective of relevant theory?

\section{Teaching Notes}

Teaching notes were required, and reviewers considered the following issues:

- A brief synopsis of the case including likely groups which would use the case.

- Comments about how the case has been used and with whom.

- Questions to be used with the case.

- Suggested answers for the questions.

- A teaching and learning plan that includes suggestions for the sequence of events, timings and description of the amount of time to be spent on various activities.

- Additional material for students and allied materials (handouts, role-play briefs, audio visual materials).

- Recommended readings and other references.

- Some discussion of alternative uses for the case.

- A disclosure of the case source and any disguises used.

Teaching notes are available to academic staff by contacting: gelkin@business.otago.ac.nz

Thanks to the Department of Management at Otago University for financially supporting this issue and particular thanks to Nancy Benington for her patience, hard work and unflappable assistance in the processes of preparing this special edition.

\section{Graham Elkin}

\section{University of Otago}

